\title{
UNA SALA DE ARBITRAJE DE INVERSIÓN PARA SURAMÉRICA Y EL CARIBE
}

\section{UMA SALA DE ARBITRAGEM DE INVESTIMENTOS PARA A AMÉRICA DO SUL E O CARIBE}

Pedro Duarte LLovera ${ }^{*}$

Resumen: En tiempos de crisis capitalista e inestabilidad global, el nuevo regionalismo alternativo surge tanto como un puente y como un escudo entre los países en desarrollo y la incertidumbre global. Desde la Cumbre de las Américas de 2004, América del Sur ha ido desarrollando una nueva identidad regional, que no encaja en los conceptos actuales de regionalismo en América del norte, Europa o Asia. Este neo regionalismo que representa ALBA, la Unión de Naciones Suramericanas (UNASUR) y la CELAC, refleja las heterogéneas configuraciones económicas, sociales y politicas de las fuerzas sociales y de orden político, que son únicas a nuestro continente. En tal sentido, se requiere una recta ordenación jurídica y la creación de un sistema integral de resolución de controversias que responda a nuestra realidad, sin la injerencia de agentes externos, pues tenemos las capacidades, las fortalezas y los juristas para construir una fuerte y poderosa neo institucionalidad de justicia que en caso de diferencias, permita entregar a este sistema de integración suramericano y sus integrantes una adecuada y eficaz seguridad jurídica, indispensable para seguir avanzando. Como parte integral del mismo se propone la creación de una Sala de Arbitraje y Mediación en materia de inversiones con carácter de permanencia e identidad suramericana y caribeña, para dar respuesta adjetiva y procesal a otras normas de relación internacional aceptadas por los países miembros, para así evitar demandas exageradas ante el CIADI, como el caso Exxon Mobil versus PDVSA.

\footnotetext{
* Abogado Cum Laude (USM). Especialista en: Derecho Procesal (Universidad de Salamanca); Derecho Corporativo (UNIMET); Formación Docente (UC). Magister en: Derecho Procesal (UCAB) y en Sociología para el Desarrollo de América Latina (UARCIS). Investigador A2 del Ministerio del Poder Popular para la Educación Universitaria, Ciencia y Tecnología de la República Bolivariana de Venezuela. Profesor de Pre y Postgrado de la Cátedra de Resolución Alternativa de Conflictos de la Facultad de Ciencias Jurídicas y Políticas de la UJAP. Consultor Jurídico de Agropecuaria Flora C.A; Ministerio del Poder Popular para la Agricultura y Tierras (MPPAT). Miembro del Frente Bolivariano de Innovadores, Investigadores y Trabajadores de la Ciencia, FREBIN Carabobo.Caracas - Venezuela. E-mail: pedroduarte_6@hotmail.com
} 
Resumo: Em tempos de crise capitalista e da instabilidade global, o novo regionalismo surge como alternativa tanto uma ponte e como um escudo entre países em desenvolvimento e incerteza global. Desde a Cúpula das Américas em 2004, a América do Sul desenvolveu uma nova identidade regional, que não se enquadram nos conceitos atuais de regionalismo na América do Norte, Europa e Ásia. Esse regionalismo neo representando ALBA, a União de Nações Sul-Americanas (UNASUL) e CELAC reflete as configurações econômicas, sociais e políticas heterogêneas de forças sociais e ordem política, que são únicas para a Europa. A este respeito, é necessária uma ordem jurídica em linha reta e na criação de um sistema global de resolução de litígios que responde a nossa realidade, sem a interferência de agentes externos, então temos as capacidades, forças e advogados para construir uma forte e poderosa instituições neo de justiça em caso de litígio, este sistema permite dar a integração sul-americana e os seus membros a segurança jurídica adequada e eficaz, o que é essencial para novos progressos. Como parte integrante da criação de uma Câmara de Arbitragem e Mediação do investimento em uma base permanente e América do Sul e Caribe identidade é proposto para atender outro adjetiva $e$ as regras processuais das relações internacionais aceites pelos países membros, assim evitar reclamações exageradas antes ICSID, conforme o caso Exxon Mobil contra a PDVSA.

Palabras clave: Regionalismo Alternativo, UNASUR, Arbitraje, Normas de Inversión

Palavras-chave: Regionalismo Alternativo, UNASUL, Arbitragem, Normas de Investimentos

\section{LAS NORMAS DE LA NUEVA INTEGRACIÓN REGIONAL: UNASUR}

En principio, debemos tener en cuenta que existen tres tipos de normas que se generarían en la UNASUR dentro del contexto de la integración propuesta: $i$.- normas de integración intergubernamental; ii.- las normas de integración comunitaria o supranacional; y, iii.- otras que no siendo exclusivas de los doce países miembros, se generan de las relaciones internacionales y globalización aceptadas por las partes, que las denominamos otras normas de relación internacional aceptadas, como el caso de materia de inversiones.

i.- Las normas de integración intergubernamental, aquellas creadas por parte del proceso integrador suramericano o por sus Estados miembros, de carácter intergubernamental, que vinculan a sus integrantes pero en condiciones diferentes que las comunitarias o supranacionales, dado que los órganos facilitadores no pueden normar ni decidir autónomamente, ni de forma supranacional, por ello la 
aplicación y acatamiento a sus países miembros no es inmediata, sino que estas deberán ser aceptadas y homologadas en ellos a través del exequátur

ii.- Por su parte, las normas de integración comunitaria o supranacional, son creadas por requerimiento, necesidad y voluntad soberana de los países miembros en función de los grandes objetivos que persigue la Integración, sean normas primarias o derivadas de carácter supranacional o comunitarias, concretadas en Tratados, Acuerdos, Protocolos, Decisiones y demás normas comunitarias, que atribuyan ciertas competencias a organismos supranacionales, para cumplir objetivos macro nacionales, superestatales o supranacionales, estas generan derechos y obligaciones a sus países miembros, órganos facilitadores y ciudadanos integrados a un proceso de integración, sean personas naturales o jurídicas, que en caso de controversia, debe resolverse para dar seguridad jurídica a los procesos de integración y los sujetos intervinientes de los mismos. La aplicación y acatamiento de sus países miembros es inmediata, no necesitan ser aceptadas y homologadas en los países miembros, es decir, no requiere exequátur.

iii.- Asimismo, tenemos otras normas de relación internacional aceptadas de los países miembros de Suramérica, que no siendo integracionistas (ni comunitarias ni gubernamentales), vinculan a los Estados o países miembros entre ellos; o entre los Estados miembros y terceros que no son países miembros, verbigracia las cláusulas o convenios sobre las inversiones $\mathrm{u}$ otras similares que nacen de convenios y otros instrumentos que suscriben los países miembros con terceros y sus particulares ${ }^{1}$. Es decir, los Tratados Bilaterales, los Contratos Administrativos, los Contratos de Inversión, que por lo general incluyen como requisito sine qua non del capital de inversión, compromisos arbitrales a foros internacionales para eventuales diferencias, prima facie.

En consecuencia, se propone un sistema integral de Justicia y Resolución de Controversias, que estará integrado por un Tribunal Rector de Justicia, que a su vez se constituya de cinco salas a saber: i.- Sala de Justicia de la UNASUR para resolver las controversias que emanen de la normativa integracionista comunitaria e intergubernamental. ii.- Sala Arbitral de la UNASUR para presentar otra opción heterocompositiva para resolver las controversias anteriores, que no sean de orden público. iii.- Sala de Casación y Nulidades de Laudos Arbitrales. iv.- Sala o Centro Arbitraje en materia de inversiones y $v$.- Sala o Centro de Mediación y espacio de Diálogo autocompositivo.

El Derecho Internacional de Inversiones consiste entonces, en un conjunto de reglas que protegen a la inversión y al inversionista

1 SAlGADO, Oswaldo. Colección Sendero Suramericano del Siglo 21.: El ABC del Derecho para la integración. Quito: EDISLAT. 2010. Tomo 1. 
extranjero frente a las acciones de los Estados receptores de la inversión. En consecuencia, podemos definir el Arbitraje de Inversión como un mecanismo alternativo de resolución de controversias, heterocompositivo no judicial, aunque sí jurídico, para el arreglo de conflictos presentes o futuros, basados en el concurso de las partes, quienes eligen por su propia cuenta, ya sea directamente o a través de mecanismos de designación acordados por ellas mismas, a terceros neutrales e imparciales, para que resuelvan sobre el choque de intereses que se les presenta; siendo el consenso y el principio de autonomía de voluntad de las partes, la regla de oro que debe quedar plasmado en un compromiso de arbitraje, por escrito.

Cuando se trata de desarrollar o promover la inversión extranjera, los intereses, las motivaciones y las aspiraciones de los inversionistas y los Estados receptores, suelen ser diferentes. Para el inversionista, la inversión es una forma de maximizar ganancias, expandir mercados, consolidar alianzas estratégicas, desarrollar etapas del proceso productivo o cualquier otra de índole empresarial. Para el Estado receptor, la inversión es una especie dentro de un género, el de fondos útiles para financiar el desarrollo. En ese género estarían también la renta, sea de recursos naturales o de tributos, los créditos y la ayuda internacional. En otras palabras, para el Estado receptor de la inversión extranjera no es más que un mecanismo de financiamiento del desarrollo, crecimiento económico, obtener tecnología de avanzada generación, activar el aparato productivo, crear empleos, disminuir la pobreza y las asimetrías, entre otros.

Ahora, cabe preguntarse, ¿Se ha cumplido con la premisa que con las inversiones extranjeras se logre el tan anhelado desarrollo y ese crecimiento económico que puede expresarse en producto interno bruto, balanza interna de pagos, balanza externa de pagos, entre otros; o más bien, una nueva dependencia de tecnología y de beneficios económicos de las grandes corporaciones en las manos de muy pocos, sin que las grandes ganancias lleguen a los pueblos?

\section{BREVE RESEÑA HISTÓRICA}

Históricamente hablando, la institución del arbitraje internacional tiene antecedentes muy remotos, ya que encontramos aplicaciones de la misma entre las repúblicas helénicas, por los consejos anfictiónicos, los cuales, aunque tuviesen orígenes y finalidades esencialmente religiosas, ejercieron, sin embargo, influencia política ${ }^{2}$.

Debemos tener presente que el arbitraje es uno de los llamados mecanismos jurídicos para la resolución pacífica de controversias, desde

2 DIENA, Julio. Derecho Internacional Público. Traducción de la 4a ed. Italiana. Barcelona: Bosch, 1948, p. 452. 
un punto de vista elemental puede decidirse que existe controversia internacional desde el momento en que hay oposición de pretensiones lo suficientemente manifestadas para poner en peligro la paz social, es decir, cuando se produce la contradicción de intereses entre dos o más Estados.

Para hablar de los primeros instrumentos de paz, las Convenciones de la Haya son una referencia obligada. El arbitraje, como procedimiento independiente de solución de controversias fue contractualmente codificado en las Convenciones de la Haya de 1899 y 1907. En ninguna de ellas se logró establecer el arbitraje con carácter compulsivo. En la primera, se reconoció la importancia del arbitraje en estos términos: "En cuestiones de naturaleza legal y especialmente en la interpretación o aplicación de convenciones internacionales, las potencias signatarias reconocen que el arbitraje es el mecanismo más efectivo, y al mismo tiempo más justo, para la resolución de controversias que no hayan podido ser arregladas por la vía diplomática”3.

Posteriormente, la Convención de 1907, que tenía por objeto sustituir a la de 1899, mejoró el procedimiento al establecer que cada una de las partes solo podía designar a un nacional como miembro del tribunal arbitral, de tal manera que el voto dirimente pasó a los tres miembros neutrales. En ese instrumento tampoco se pudo establecer lo que constituía entonces una aspiración, es decir, el establecimiento de una corte permanente de arbitraje, que había sido el preludio de la Corte Internacional de Justicia.

En pocas palabras, las dos convenciones de la Haya, constituyen un antecedente fundamental de todo análisis sobre el procedimiento arbitral.

Antes del aparecimiento de órganos comparativamente adelantados como la Corte Internacional de Justicia, la Sociedad de las Naciones y las Naciones Unidas, el arbitraje internacional no aparece primordialmente como una contribución importante y ampliamente técnica para el arreglo de controversias de índole rutinaria. Simbolizó más bien la esperanza mesiánica de sujetar al Estado soberano, con su actitud de ser el juez único de su causa, a la imparcialidad olímpica del juicio de una tercera parte como medio de abolir a guerra. Gran parte del descontento actual respecto del arbitraje surge ya sea de la nostalgia de esas esperanzas pasadas, ahora ya irrealizables, o del ingente deseo de escapar del tremendo conflicto de las versiones nacionales de verdad $\mathrm{y}$ justicia en el mundo de la mitad del siglo $\mathrm{XX}^{4}$.

En 1919, se creó la Corte Permanente de Justicia y la Sociedad de

3 VALENCIA RODRÍGUEZ, Luis. Principios de las Naciones Unidas. Quito: Editorial Casa de la Cultura Ecuatoriana, 1972. p. 106.

4 MORENO LOAYZA, Guadalupe. El Tribunal de Justicia del Acuerdo de Cartagena como medio jurídico de solución de controversias: estudio 4. Quito: Publicaciones del Tribunal, 1987. 
naciones. Al término de la segunda guerra mundial en 1945, se creó la ONU y se restableció el anterior Tribunal con el nombre de Corte Internacional de Justicia (también llamado Tribunal Permanente de Justicia Internacional), con sede en la Haya-Holanda. Lo integran jueces de 15 Estados miembros, que son elegidos por la Asamblea y el Consejo de Seguridad de las Naciones Unidas. Entran en su competencia los casos previstos en la carta y aquellos que le son sometidos de común acuerdo por las partes. Más allá de esta jurisdicción contenciosa la Corte de acuerdo al artículo 97 de la carta, tiene jurisdicción consultiva. La Asamblea General o el Consejo de Seguridad, pueden solicitar opiniones consultivas a la Corte sobre cualquier cuestión jurídica. Las decisiones de los Tribunales Internacionales como es el caso, tienen efecto solamente entre las partes en litigio y en cuanto al caso resuelto (Art. 59 del Estatuto).

El Estatuto de la Corte Internacional de Justicia, fue elaborado en forma de Tratado multilateral y se considera que tiene una notable significación jurídica, ya que casi la totalidad de los Estados han llegado a ser parte del mismo ${ }^{5}$. La Corte tiene como función decidir conforme al derecho internacional las controversias que le sean sometidas, aplicando: las convenciones internacionales, la costumbre internacional, los principios generales del derecho y las decisiones jurisprudenciales como medio auxiliar.

En consecuencia, una tendencia que se percibe en estos acuerdos es la inclusión de mecanismos de resolución de controversias como estrategia para resolver las diferencias que se presentan en la aplicación de los acuerdos así como para reforzar el cumplimiento de las obligaciones adquiridas. Este mundo es complejo y dinámico, por un lado, aún cuando se pueden observar amplias tendencias, cada mecanismo en cada acuerdo de integración es un microcosmos. Al realizar un inventario de toda esa gama de enfoques y matices que ofrecen tal cantidad de mecanismos, podemos observar que estamos frente a una materia cuyo análisis es difícil por sus múltiples implicaciones y ramificaciones de todo orden.

Sin duda alguna, hablar de arbitraje de inversión necesariamente es hablar del Centro Internacional de Arreglo de Diferencias Relativas a Inversiones (CIADI), como un foro establecido en 1966, para facilitar el arreglo de disputas entre gobiernos e inversionistas extranjeros, siendo su objetivo principal el de ayudar a promover mayores niveles de flujos de inversión a nivel internacional, dependiente del Banco Mundial.


p. 18. 
3. CONTROVERSIA EXXON MOBIL VERSUS PETRÓLEOS DE VENEZUELA (PDVSA) ANTE EL CENTRO INTERNACIONAL DE ARREGLO DE DIFERENCIAS RELATIVAS A INVERSIONES (CIADI)

La controversias judicial entre Exxon Mobil versus Petróleos de Venezuela (PDVSA), se inicia legalmente cuando la transnacional estadounidense introduce una petición de arbitraje ante el Centro Internacional de Arreglo de Disputas Relativas a Inversiones (CIADI) en el mes de agosto del año 2007, en la ciudad de New York. Todo ello, con el fin último de obtener del Alto Tribunal de Inglaterra y Gales, con sede en Londres, la orden judicial de una medida cautelar de congelamiento de bienes de PDVSA a concurrencia de un monto de 12.000 millones de dólares.

Luego de transcurridos cuarenta días, después de que la petrolera Exxon Mobil ganara una orden de un tribunal británico para congelar activos de Petróleos de Venezuela (PDVSA) por hasta 12.000 millones de dólares, el 18 de marzo de 2008, Venezuela salió victoriosa ante los hechos que envolvieron la agresión, emprendida por la transnacional estadounidense contra PDVSA. Un intento de sabotaje en el que se comprobó jurídicamente la realidad de los hechos.

\subsection{De los Hechos}

A continuación un relato de los hechos que rodearon la controversia por el pago de regalías de la transnacional Exxon-Mobil.

12 abril 2007: el presidente eterno de la República Bolivariana de Venezuela, Comandante Hugo Chávez Frías, en un acto alusivo a la conmemoración de los cinco años del golpe de Estado de 2002, anunció la decisión de restituir a la nación las ganancias por concepto de regalías petroleras, al regresar al poder del Estado los pozos petroleros que hasta entonces se encontraban en manos de transnacionales. Las asociaciones estratégicas que deberían pasar al nuevo esquema de empresas mixtas eran: Petrozuata, Ameriven, Cerro Negro y Sincor, en las que además participan las compañías Total, Statoil, Conoco Phillips, Chevron, Exxon-Mobil y BP.

25 abril 2007: el Ministerio del Poder Popular Para Energía y Petróleo firmó los memorandos de entendimiento con empresas transnacionales que operaban en la Faja del río Orinoco para la creación de empresas mixtas y anunció que a partir del primero de mayo de ese año, Venezuela asumirá el control de los yacimientos de petróleo en la Faja del Orinoco, al sur del país.

29 abril 2007: autoridades de la estatal venezolana Petróleos de Venezuela (PDVSA) anunciaron la instalación de los comités de 
transición en la Faja del Orinoco para ocupar la producción desde el $1^{\circ}$ de mayo de 2007, cuando el Estado asumiría la administración mayoritaria de esos campos.

$1^{\circ}$ mayo 2007: el Estado venezolano asumió la administración mayoritaria de los campos petroleros.

26 junio 2007: la estatal Petróleos de Venezuela (PDVSA) firmó un memorando de entendimiento con las transnacionales ChevronTexaco, Statoil, Total, BP, Eni y Sinopec e Inelectra, con el fin de dar inicio al funcionamiento de empresas mixtas, en el marco de los convenios de asociación de la Faja Petrolífera del Orinoco. En el caso de Exxon Mobil y Conoco Phillips, las únicas dos empresas que no aceptaron la negociación con Pdvsa, por lo cual se anunció que estas terminarían su participación en los negocios de la Faja del Orinoco.

07 febrero 2008: la petrolera Exxon-Mobil Corp obtuvo una orden de medida cautelar de un tribunal británico por medio de la cual ordenaba congelar activos de Petróleos de Venezuela

(PDVSA) a concurrencia de un monto de 12.000 millones de dólares. La multinacional petrolera estadounidense Exxon-Mobil (se llamaba antes Esso) junto con sus rivales BP y Shell para constituyen un cártel para dominar el mercado mundial. Actualmente lucha por controlar los recursos petroleros venezolanos.

08 febrero 2008: desde un ángulo político el sociólogo estadounidense James Petras aseguró que estas acciones de Exxon Mobil eran "un esfuerzo para derrocar al Gobierno" del presidente, Hugo Chávez y de esta manera "revertir las políticas petroleras nacionales sobre el control del petróleo". El embajador de Venezuela de ese entonces, ante el Reino Unido y ex ministro, Samuel Moncada, consideró "un golpe de propaganda económica" las afirmaciones de Exxon Mobil, sobre el supuesto congelamiento de 12 mil millones de dólares de activos de PDVSA.

09 febrero 2008: en el mismo terreno político, cientos de trabajadores de PDVSA de Petromonagas, antigua Operadora Cerro Negro, se reunieron en las áreas operacionales de la empresa para rechazar las pretensiones de la transnacional.

10 febrero 2008: el presidente, Hugo Chávez, advierte a Estados Unidos que no le vendería "ni una gota de petróleo", de continuar los ataques económicos contra su país, como la demanda introducida por la gigante petrolera Exxon Mobil contra la estatal Petróleos de Venezuela (PDVSA), a los que calificó como una "guerra económica".

11 febrero 2008: el Congreso Bolivariano de los Pueblos, a través de su Secretaría de Organización Latinoamericana Caribeña, condena y repudia a la empresa Exxon-Mobil por su agresión contra (PDVSA), entendiendo que la acción legal promovida por la empresa estadounidense carece de validez. 
11 febrero 2008: integrantes del Frente Bolivariano de Trabajadores de Petrocedeño, antigua Sincrudos de Oriente (Sincor), rechazaron las acciones de la transnacional Exxon Mobil. El movimiento estudiantil venezolano respaldó acciones del Gobierno Bolivariano en el ejercicio de la soberanía plena sobre el petróleo, al tiempo que repudió las acciones de la Exxon Mobil como mecanismo económico del imperio norteamericano, en su intento de desestabilizar a Venezuela y sus relaciones económicas en el mundo.

12 febrero 2008: frente a las acciones de hostigamiento jurídicoeconómico emprendidas por Exxon Mobil contra PDVSA, y como un acto de reciprocidad, se anunció la "suspensión de las relaciones comerciales y el suministro de crudos y productos" a la transnacional estadounidense Exxon- Mobil. La comisión de Energía y Minas de la Asamblea Nacional respalda medidas del Gobierno sobre Exxon. Profesionales, estudiantes, integrantes de misiones y consejos comunales, así como de diferentes organizaciones del estado Zulia, toman de forma pacífica la estación de servicio Exxon-Mobil de esa entidad, en rechazo a las medidas adoptadas por dicha transnacional en contra de PDVSA. En Puerto La Cruz, Estado Anzoátegui, los trabajadores del mejorador de crudos de la empresa Petromonagas en la entidad se declararon en Asamblea permanente frente a una acción de guerra económica contraVenezuela.

13 febrero 2008: calificadoras de riesgo minimizan impacto de acciones judiciales de Exxon Mobil. De acuerdo con los análisis difundidos por Standard and Poor's, una de las más importantes agencias internacionales de calificación de riesgo, PDVSA no verá afectadas sus operaciones en el mercado mundial de hidrocarburos, tras las acciones judiciales emprendidas por Exxon-Mobil contra la estatal petrolera venezolana. Fitch Ratings indicó que "la medida judicial obtenida por Exxon Mobil tiene un impacto mínimo sobre las operaciones de PDVSA, así como sobre su calidad crediticia y flexibilidad financiera a corto plazo". Mientras, Lehman Brothers afirmó que "sería improbable una cesación de pagos de deuda por parte de PDVSA".

14 febrero 2008: el Ministro de Energía y Petróleo de Venezuela, Rafael Ramírez, expuso ante la Asamblea Nacional los documentos que demuestran los vínculos de la vieja dirigencia de la estatal PDVSA con las corporaciones internacionales de hidrocarburos, que permitió, en detrimento de la soberanía venezolana, que empresas como Exxon Mobil puedan demandar a la República en tribunales de arbitraje internacional.

16 febrero 2008: el presidente de Nicaragua, Daniel Ortega, llamó a los países de Petrocaribe a unirse en rechazo a la agresión de ExxonMobil contra PDVSA, la principal industria nacional de Venezuela, y aseguró que detrás de la disputa judicial entablada por la transnacional 
petrolera estadounidense está una estrategia de Washington para debilitar la unidad latinoamericana y caribeña.

17 febrero 2008: el presidente Hugo Chávez, aseguró que las versiones que circulan en medios de comunicación sobre una supuesta debilidad de la principal industria nacional, PDVSA son totalmente falsas, y enfatizó que pese a años de coloniaje y explotación rapaz de los recursos venezolanos, ahora es cuando queda petróleo en el mayor yacimiento de crudo pesado del mundo: la Faja del Orinoco. Asimismo declaró que Venezuela no está sola ante la arremetida de la transnacional estadounidense Exxon Mobil.

28 febrero 2008: el Tribunal Superior de Londres escuchó por vez primera, en una audiencia oral y pública que se prolongó hasta el 3 de marzo, los alegatos de la estatal Petróleos de Venezuela PDVSA que pide se desestime la medida cautelar solicitada por la gigante privada estadounidense Exxon Mobil, para congelar 12 mil millones de dólares de los activos de la empresa-suramericana.

29 febrero 2008: el presidente Hugo Chávez, aseguró que la petrolera estadounidense Exxon Mobil "fracasará" en su intento de "agredir" a Venezuela, al hacer referencia a la acción judicial de esa transnacional ante tribunales extranjeros para intentar congelar activos petroleros venezolanos por 12 mil millones de dólares.

04 marzo 2008: una marcha de protesta encabezada por parlamentarios británicos recorrió las calles de Londres, al grito de "Exxon no, Venezuela sí ", por el litigio que la transnacional estadounidense lleva en contra de la estatal Petróleos de Venezuela PDVSA.

05 marzo 2008: al cierre de la 148 conferencia celebrada en Viena, Austria, la OPEP, organización que agrupa a los 13 mayores exportadores de petróleo del mundo, manifestó su 'apoyo a Venezuela y a su compañía nacional de petróleo, PDVSA, en el ejercicio de sus derechos soberanos sobre sus recursos naturales", por el caso de Exxon Mobil. Además, rechazó tener algo que ver con el elevado precio del crudo, que está por encima de los 100 dólares, por lo que decidió mantener los actuales niveles de producción. El gobierno de la República de Gambia, a través de su canciller, Crispin Grey Jonson, expresó su respaldo y solidaridad a la posición adoptada por el presidente de la República Bolivariana de Venezuela, Hugo Chávez Frías, frente a la agresión de la gigante petrolera.

06 Marzo 2008: el presidente de la Comisión de Energía y Minas de la Asamblea Nacional, Ángel Rodríguez, afirmó que los tribunales ingleses, estadounidenses y holandeses que pretenden congelar activos de Petróleos de Venezuela PDVSA violan las resoluciones de la Organización de las Naciones Unidas.

10 marzo 2008: Venezuela está a la espera del fallo del Tribunal 
Superior de Londres en torno al litigio que mantienen la petrolera estadounidense Exxon Mobil y la estatal venezolana Petróleos de Venezuela, en la que se decidirá la legalidad de la solicitud hecha por la multinacional norteamericana para intentar congelar activos por hasta 12 mil millones de dólares a PDVSA.

13 marzo 2008: el ministro de Energía y Petróleo venezolano, Rafael Ramírez, aseguró desde Canadá que su país se convertirá en la mayor reserva de crudo pesado del mundo, "en virtud del proceso de cuantificación y certificación que se lleva a cabo en la Faja Petrolífera del Orinoco", cuya nacionalización hizo que la petrolera estadounidense Exxon Mobil demandara a la estatal Petrolera.

14 marzo 2008: el juez británico que debía fallar esta semana sobre el litigio en Londres entre el grupo petrolero estadounidense ExxonMobil y la compañía estatal venezolana PDVSA, postergó su veredicto para la semana próxima.

15 marzo 2008: la Comisión de Energía y Minas de la Asamblea Nacional emitió un comunicado de prensa donde señala que la tardanza del Tribunal de Londres en revocar la

decisión que pretende congelar activos de Petróleos de Venezuela por 12 mil millones de dólares es un verdadero terrorismo judicial.

18 marzo 2008: un tribunal británico rechazó la solicitud de congelación preventiva de 12 mil millones de dólares de activos de la estatal Petróleos de Venezuela con alcance mundial, lo que se conoce como la infame "mareva injunction" que había pedido de la estadounidense Exxon Mobil a un Tribunal Superior de Inglaterra y Gales, dando la victoria ganada sobre "el chantaje" que pretendía llevar hasta el final la transnacional Exxon Mobil.

El análisis jurídico de esta controversia, debe tomar en cuenta la naturaleza tanto sustantiva, que no es otra cosa que el derecho invocado; como la naturaleza procesal del conflicto, que se refiere a los procedimientos y a la jurisdicción utilizada.

\subsection{Del Derecho}

El análisis jurídico de esta controversia, debe tomar en cuenta la naturaleza tanto sustantiva, que no es otra cosa que el derecho invocado; como la naturaleza procesal del conflicto, que se refiere a los procedimientos y a la jurisdicción utilizada.

\subsubsection{De la Mareva Injunction y la Naturaleza Procesal}

En agosto de 2007, la empresa Exxon-Mobil introduce una petición de arbitraje ante el Centro Internacional de Arreglo de Disputas Relativas a Inversiones (CIADI), en la ciudad de New York. Frente a 
esta situación PDVSA acudió a constituir el Comité Arbitral; para seguir el procedimiento relativo al nombramiento de los árbitros tanto de Exxon Mobil como de PDVSA. Todo ello, con la finalidad de obtener con posterioridad la instrumentalidad procesal necesaria, para armar la argucia jurídica ante un Alto Tribunal de Inglaterra y Gales, con sede en Londres, que ordenó una medida cautelar de congelamiento de bienes de PDVSA con alcance mundial a concurrencia de un monto de 12.000 millones de dólares, la denominada Mareva Injunction.

Al referirnos al término inglés injunction cuya traducción al español significa entredicho. Legalmente, se trata de un mandato judicial provisional mediante el cual un Juez emite una orden o requerimiento de obligatorio cumplimiento para que la parte obligada, en forma temporal, haga o se abstenga de hacer determinados actos, so pena de ser sancionado civil o penalmente e incluso pagar elevadas cantidades en concepto de daños y perjuicios. Para que el requerimiento sea procedente basta con demostrar ante la autoridad judicial la alta probabilidad de éxito a los méritos del asunto y el riesgo de que la ausencia del mandato provoque al solicitante daños irreparables. Generalmente estas medidas se acuerdan inaudita alteran parte, es decir, a espaldas de la parte en quien de la que se solicita, lo que le da ese carácter de sorpresa, coloreando el escenario perfecto para el terrorismo judicial. En todo caso, la injunction es una medida cautelar de carácter procesal que se asimila a las medidas preventivas, embargo o prohibición de enajenar y gravar o a las cautelares innominadas contempladas en nuestro procedimiento civil.

Ahora bien, mareva es la denominación de un régimen también provisional cautelar previsto en las jurisdicción del Commonwealth, $y$ su finalidad específica es la de congelar bienes de un demandado para que éste no disipe sus bienes con fines de insolvencia y de frustrar el futuro y eventual cumplimiento de una condena.

Esta acción procesal preventiva debe su nombre a la orden de congelación de bienes dictada por un Juez del Reino Unido a solicitud de la empresa Mareva Compañia Naviera Internacional S.A.

En cuanto a su naturaleza jurídica tenemos que esta figura no constituye una garantía de fiel cumplimento, ni un medio de presión hacia el deudor y mucho menos crea al solicitante expectativas de derechos de propiedad sobre los bienes del deudor congelados. La orden Mareva se aplica en aquellos casos en que el actor demuestra que la otra parte persigue frustrar el efecto de una sentencia inminente y fulminante, o que está abusando de los procedimientos judiciales. Las pruebas son promovidas en una etapa previa del juicio y básicamente son declaraciones juradas.

A menudo la aplicación del régimen Mareva va acompañada de una orden anton piller, que en nuestro derecho procesal equivale a la 
acción por retardo perjudicial, es decir, la demanda tendiente a recabar y proteger las pruebas que puedan desaparecer por obra del tenedor de las mismas o por efecto del tiempo. El peligro que representa estas órdenes para un deudor es, por un lado, que puedan acumularse varias hasta congelar totalmente a una empresa, y por otro, que se revele información confidencial ${ }^{6}$. Esta ha sido pues la instrucción aplicada a PDVSA y que afortunadamente para los venezolanos ha sido revocada básicamente por incompetencia territorial de la jurisdicción de los tribunales de ese País.

Es así como Exxon-Mobil obtiene la medida cautelar de congelamiento a su favor, que tiene un carácter excepcional y más aún por un monto tan elevado, además que deben existir suficientes indicios de peligro de dilapidación que no existen en el caso concreto, es decir, deben existir suficientes elementos de verosimilitud que demuestren el periculum in mora, que no es otra cosa que el peligro en la mora; además del fomus bonis iuris, que es la apariencia del buen derecho que se reclama; y el pericumum in damni, elementos y supuestos que no se dan en este caso, alegados por la transnacional.

Es muy relevante destacar, que según el informe de gestión anual de PDVSA del año 2008, la producción de la estatal petrolera se calculo en 152.000 millones de barriles, calculados en 126.363 millones de dólares, por lo que hay que tomar en cuenta el aumento de la conmodities. La medida tiene múltiples lecturas. En lo económico, es un eslabón más de la cadena de agresiones del capital transnacional contra Venezuela, que buscaba obtener la posesión y el control de su industria petrolera. En lo político, es un nuevo intento de desestabilizar el gobierno democrático de Hugo Chávez Frías. En lo estratégico, es un avance del bloqueo ya impuesto por Estados Unidos a nuestras compras. En lo jurídico se trata, ni más ni menos, de un intento de arrebatarle a Venezuela su soberanía de jurisdicción, es decir, el derecho a decidir sus controversias utilizando sus propias leyes y tribunales. Soberanía es la potestad de un Estado de sancionar sus propias leyes, aplicarlas e interpretar mediante sus órganos jurisdiccionales las controversias que surjan sobre dicha aplicación. Basta eliminar una de estas potestades para aniquilar la soberanía.

Para comprender el significado de este debate en América Latina es preciso hacer un poco de historia. La invasión de Francia e Inglaterra a México en 1861 alertó la conciencia de los juristas latinoamericanos. Ya para 1868 el diplomático internacionalista argentino Carlos Calvo desarrolló en su obra Derecho Internacional Teórico Práctico de Europa y América la doctrina de que un Estado independiente, en virtud del principio de igualdad de los Estados, no podía estar sometido a la

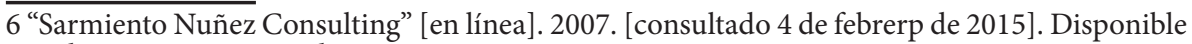
en: <http://www.snconsult.com/>. 
ingerencia de otros Estados. Afirmó asimismo que los extranjeros no podían gozar de mayores derechos y privilegios que los nacionales, y debían solucionar sus controversias ante los tribunales internos del Estado territorial. Convencidos por esta doctrina, varios países latinoamericanos, entre ellos Bolivia, Honduras y Venezuela, incluyeron en sus constituciones y legislaciones una norma que fue conocida como "Cláusula Calvo", relativa a los contratos celebrados con inversionistas extranjeros, que impedía a éstos resolver las controversias sobre tales pactos acudiendo al llamado "recurso de protección diplomática" en el exterior, y les imponía dirimir sus reclamaciones única y exclusivamente en los tribunales del Estado receptor y de acuerdo con las leyes de éste.

Siguiendo esta doctrina, la Constitución de la República de Venezuela sancionada el 29 de marzo de 1901 dispone en su artículo 139 lo siguiente: "Ningún contrato de interés público celebrado por el Gobierno Federal o por el de los Estados, por las Municipalidades o por cualquier otro Poder Público, podrá ser traspasado, en todo o en parte, a gobierno extranjero; y en todos ellos se considerará incorporada, aunque no lo esté, la cláusula siguiente: 'Las dudas y controversias de cualquier naturaleza que puedan suscitarse sobre este contrato y que no puedan ser resueltas amigablemente por las partes contratantes, serán decididas por los Tribunales competentes de Venezuela de conformidad con sus leyes, sin que por ningún motivo o por ninguna causa puedan ser origen de reclamaciones extranjeras. Las sociedades que en ejercicio de dichos contratos se formen, deberán establecer domicilio legal en el país, para todos sus efectos, sin que esto obste para que lo puedan tener a la vez en el extranjero". A los constituyentes de esa época no les faltaban patriotismo ni previsión. Año y medio después, el 2 de diciembre de 1902, las flotas de los imperios inglés, alemán e italiano bloquearon y bombardearon Venezuela para cobrar por la fuerza nuestra Deuda Externa. Desde entonces, para evitar atropellos de esa índole generados por contratos con extranjeros o deudas derivadas de ellos, figura en todas las constituciones venezolanas una norma semejante, como por ejemplo el artículo 49 de la Constitución de 1936, que reza textualmente: "Ningún contrato de interés público celebrado con el Gobierno Federal o con los de los Estados, o con las Municipalidades o con cualquier otro Poder Público, podrá ser traspasado, en todo ni en parte, a Gobiernos extranjeros, y en todos ellos se considerará incorporada, aunque no estuviere expresa, la cláusula siguiente: "Las dudas y controversias de cualquier naturaleza que puedan suscitarse sobre este contrato y que no puedan ser resueltas amigablemente por las Partes contratantes, serán decididas por los Tribunales competentes de Venezuela, de conformidad con sus leyes, sin que por ningún motivo ni causa puedan ser origen de reclamaciones extranjeras". Tampoco podrán hacerse dichos contratos con Sociedades no domiciliadas legalmente en Venezuela, ni admitirse 
el traspaso a ellas de los celebrados con terceros".

Los constituyentes de 1999 replicaron exactamente en el artículo 151 la citada norma del 127 de la Constitución de 1961. Cito:

En los contratos de interés público, si no fuere improcedente de acuerdo con la naturaleza de los mismos, se considerará incorporada, aun cuando no estuviere expresa, una cláusula según la cual las dudas y controversias que puedan suscitarse sobre dichos contratos y que no llegaren a ser resueltas amigablemente por las partes contratantes, serán decididas por los tribunales competentes de la República, de conformidad con sus leyes, sin que por ningún motivo ni causa puedan dar origen a reclamaciones-extranjeras.

En consecuencia, la frase..."si no fuere improcedente de acuerdo con la naturaleza de los mismos..." es precisamente una salvaguardia de los intereses de Venezuela pues en el caso del petróleo y otros recursos naturales del país es imposible negar su calidad de bien de uso público, y por tanto sería improcedente en términos procesales discutir siquiera la competencia de los tribunales de la República en la resolución de los conflictos cuando no se ha llegado a un acuerdo amigable entre las partes. En todo caso, el régimen jurídico actual no nos deja indefensos. Para someternos a tribunales o árbitros internacionales, debería la ExxonMobil demostrar que los contratos por los cuales ahora se nos demanda no están sometidos a la Constitución porque "fuere improcedente de acuerdo con la naturaleza de los mismos", cosa difícil de sostener e imposible de probar. Es evidente que se trata de acuerdos celebrados con una empresa venezolana, propiedad íntegra de la República Bolivariana de Venezuela, para explotar recursos naturales venezolanos, con instalaciones radicadas en Venezuela, trabajadores mayoritariamente venezolanos y con disfrute de servicios públicos, dotación de seguridad jurídica y protección venezolanos. Nada puede disponer sobre esta materia un tribunal o junta arbitral británico o de cualquier otro país. Mucho menos podría alegar que no son contratos de interés nacional los referentes a la explotación de un recurso propiedad de la República. Así hemos defendido tradicionalmente el atributo de soberanía de jurisdicción, vale decir, el derecho de Venezuela de decidir según sus propias leyes y por sus propios tribunales las controversias sobre los contratos de interés público.

Estas disposiciones sensatas y patrióticas han encontrado desarrollo en normas más recientes, y de alcance latinoamericano. Así, el Pacto Andino en el artículo 50 de su Código de Inversiones Extranjeras prohíbe a los Estados miembros acordar a los inversionistas extranjeros un tratamiento más favorable que el acordado a los nacionales; y en el artículo 51 impone no introducir en un instrumento aplicable a los 
inversionistas extranjeros ninguna cláusula que establezca un mecanismo internacional para resolver diferendos en materia de inversiones. Debemos añadir que el Protocolo de Cartagena de Indias del 5 de diciembre de 1985, que reforma la Carta de la Organización de Estados Americanos (OEA), declara en forma explícita en su artículo 35 que las empresas transnacionales y la inversión privada extranjera están sometidas a la legislación y a la jurisdicción de los tribunales nacionales competentes de los países receptores. Asimismo, este principio es acogido en el dictamen sobre las empresas transnacionales del Comité Jurídico Interamericano de 1976, y también en la Carta de Derechos y Deberes Económicos de los Estados de las Naciones Unidas de 1974. En resumen, la sentencia del juez Paul Walker del Alto Tribunal de Inglaterra y Gales de revertir la medida cautelar de congelamiento tiene un efecto inmediato; y es una buena noticia no sólo para Venezuela sino también para los países pequeños que manejan recursos naturales, ya que la corte dio la razón a Venezuela, al reconocer su soberanía sobre sus propios recursos.

Igualmente, la decisión del juez en este caso va a sentar precedentes legales, que durante la audiencia argumentó además que el litigio entre PDVSA y la petrolera estadounidense está además en proceso de arbitraje ante una corte de Nueva York, por lo que la corte inglesa estaría abusando de sus poderes al mantener la orden de congelamiento de fondos contra una de las partes.

\subsubsection{Naturaleza Sustantiva}

En el sistema concesional venezolano, el Estado teniendo en virtud de su alta potestad administrativa para disponer los recursos naturales, las otorga en concesión teniendo presente el interés de la sociedad pero conservando el ius abutendi, lo cual significa que el Estado sólo concede a los particulares, el derecho de explotar la mina sin desprenderse del dominio originario. El Estado se desprende solamente del ius utendi y fruendi para que el particular explore, explote y aproveche las sustancias minerales de la concesión, condicionando la vigencia y subsistencia de ese derecho a la obligación de trabajarla en la forma que establece la Ley Minera y en cuanto al ius abutendi, el Estado lo mantiene en suspenso mientras se cumple la obligación de amparo. En resumen, el Estado no puede desprenderse del objeto de la concesión minera, con lo cual se reafirma el derecho del Estado venezolano para cobrar regalía o royalty a Exxon Móbil.

Según la doctrina, jurisprudencia y legislación a nivel mundial, el Estado o Nación, cuando no se lo limita legalmente nunca pierde (o cede) la "dominicalidad pública minera sobre los recursos mineros" ni desaparece, al otorgar la concesión e incluso bajo la expresión de 
"propiedad minera" que el particular obtiene en un procedimiento adjetivo y procesal ante el respectivo Juez de Letras y no por la Autoridad Minera.

La relación entre el Estado o Nación que otorga y concede el derecho minero al particular debe considerarse como una relación de derechos personales originados en el marco del derecho públicoadministrativo, donde el Estado atribuye al particular amplias y variadas facultades y atribuciones (incluso transmitir y transferir), pero siempre conservando el Estado su alto dominio inalienable e imprescriptible sobre los recursos. Las potestades jurídicas sometidas al sistema del derecho público son distintas respecto del privado. Por último, el dominio del Estado siempre ha tenido el carácter de patrimonial/regalista tal como estuvo establecido en la legislación española (Ordenanzas de Minas de Nueva España).

En Venezuela, desde la época de la independencia se ha establecido que la propiedad de las minas y yacimientos corresponde al Estado, este sistema fue heredado de las antiguas leyes coloniales que atribuían a los reyes esta propiedad.

La propiedad del Rey fue sustituida por la propiedad dela República Bolivariana de Venezuela, quien al constituirse como un Estado independiente declaro su propiedad sobre el patronato eclesiástico, la propiedad de las tierras baldías y la propiedad de las minas.

En Venezuela han regido dos sistemas de regulación de los hidrocarburos, el sistema regalista y el dominal, el primer sistema es aquel que atribuye la propiedad de las minas al Estado, estando este obligado a otorgar concesiones o derechos de explotación a particulares que hayan cumplido con los requisitos de la ley. El segundo sistema, es cuando el propio Estado explota directamente el yacimiento por medio de terceros escogidos a su libre elección, a quienes otorga facultativamente el derecho de explotación.

Este sistema regalista se mantuvo en el país hasta el Código de Minas de 1904, donde se excluye a los hidrocarburos de la modalidad de concesiones obligatorias y comienza a regir en Venezuela el sistema dominal.

En resumen, actuando conforme a lo establecido en sus contratos y el compromiso arbitral, Conoco Phillips y Exxon Mobil acudieron al arbitraje internacional. Exxon Mobil exigía una indemnización por las pérdidas en activos confiscados y las ganancias que dejo de percibir por el convenio. La compañía petrolera estadounidense acudió a diversas instancias internacionales como la Cámara de Comercio Internacional (CCI) y el Centro Internacional de Arreglo de Diferencias Relativas a Inversiones (CIADI).

En el CCI, Exxon Mobil apertura un procedimiento en contra de Pdvsa por incumplimiento del contrato que le otorgaba una 
participación de 41,67\% en el campo de Cerro Negro, lo cual significaba un promedio de $120.000 \mathrm{~b} / \mathrm{d}$. Al mismo tiempo inició un laudo arbitral en el Ciadi en contra de la República Bolivariana de Venezuela, por violar el Tratado Bilateral de Inversiones firmado entre Venezuela y los Países Bajos, ya que Exxon Mobil operaba en Cerro Negro a través de una filial holandesa, valiéndose de la constitución de empresas en las Antillas del Caribe.

El fallo del laudo arbitral emitido por la CCI en el 2012 le otorgó a Exxon Mobil el pago de 908 millones de dólares por concepto de indemnización, de los cuales la estatal petrolera solo debió cancelar 255 millones, tras algunos descuentos. Esto se debió a que Exxon Mobil le debía a Pdvsa 191 millones de dólares por pagos que ésta hizo para la realización de proyectos en Cerro Negro; más 300 millones de dólares que fueron congelados en las cuentas de Pdvsa en New York por acciones legales llevadas a cabo por la transnacional; y finalmente 160 millones de dólares provenientes de reconvenciones. El plazo de pago otorgado fue de 60 días.

Las autoridades venezolanas consideraron que el fallo fue un triunfo para el país, ya que Exxon Mobil exigía el pago de 12 mil millones de dólares, es decir, 11.093 mil millones más de lo previsto por la CCI.

Inicialmente Exxon Mobil exigía el pago de 20 mil millones de dólares pero redujo la cifra a 10 mil millones de dólares. En octubre del 2014, el Ciadi emitió su laudo arbitral estableciendo el pago de 1.600 millones de dólares para Exxon Mobil, en compensación por la pérdida de sus activos. Para evitar la "doble indemnización", Exxon Mobil deberá hacer un descuento a Venezuela por los 908 millones de dólares pagados en el 2012.

De cualquier forma, estamos asistiendo a una auténtica revolución en materia de resolución de controversias en razón de inversiones entre un Estado y un inversor extranjero que, no por esperada y tardía, deja de ser sorprendente. El punto de partida lo constituye el elevado número de demandas que afectan, en la actualidad, a los Estados latinoamericanos; demandas que a veces presentan un sustento muy cuestionable, con resultados muy discutibles, que invitan a la reflexión a todos los seguidores del sistema instaurado por el Banco Mundial, a través del Convenio de Washington y que supuso la creación del CIADI. Estas cifras han llevado a que los países latinoamericanos estén tomando otra actitud, completamente activa ante este sistema, proponiendo diversas opciones del más variado calado.

El CIADI perdió su objetivo inicial, al beneficiar a diversas organizaciones, empresas y transnacionales, por ser conocida más como un factor capitalista que social; demás de cuestionar la neutralidad e imparcialidad inherente a la justicia, como valor superior de cualquier ordenamiento jurídico. Uno de los principales argumentos para sostener esto es la base jurídica que el propio CIADI toma para la resolución de las demandas que le son presentadas ante los tribunales arbitrales constituidos 
por el CIADI; solamente toman a los tratados bilaterales de protección de inversiones, y el Convenio de Washington de 1996, constitutivo de este organismo, para resolver las causas presentadas, dejando de lado toda otra normativa existente, sea esta interna del Estado receptor de la inversión (incluyendo las propias Constituciones Políticas de los Estados ) o mismo la normativa proveniente del Derecho Internacional Público (que incluye, por ejemplo, los Derechos Humanos).

Por ello, países como Bolivia (2007), Ecuador (2009) y Venezuela (2012) han tomado la decisión de denunciar el convenio constitutivo (Convenio de Washington de 1966) y retirarse del organismo, lo cual ha despertado algunos problemas, ya que estos acuerdos los TBIs en su mayoría, poseen cláusulas de ultra-actividad, que por más que un Estado desee salirse de estos acuerdos, estos funcionen durante un período extra de generalmente, 10 años más.

De acuerdo a informes del CIADI durante el ejercicio fiscal 2014, y de acuerdo a los sectores económicos presentes en los nuevos procedimientos, las diferencias de inversión iniciadas en el ejercicio fiscal 2014 se refirieron a una gran variedad de sectores económicos del Banco Mundial; destacando que no es casual que el sector de petróleo, gas y minería, mantuvo su posición predominante, con el $35 \%$ de casos registrados en el ejercicio fiscal 2014.

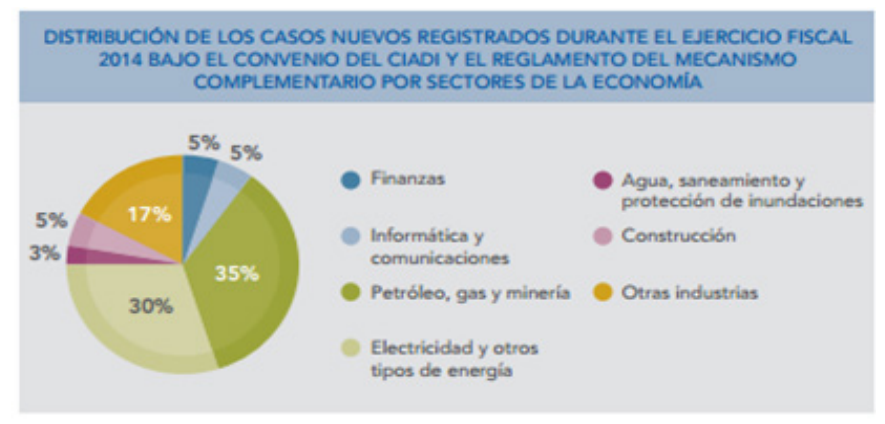

\section{UNA SALA DE ARBITRAJE DE INVERSIÓN PARA SURAMÉRICA Y EL CARIBE}

Una vez que conocemos la aplicación de este mecanismo heterocompositivo de resolución de conflictos en la esfera de tratados bilaterales de inversiones a lo largo de la historia hasta la actualidad, se puede observar que América del Sur no cuenta con un "Centro de resolución de controversias en materia de inversiones, de esto surge la propuesta por parte de la UNASUR en su creación, la cual ha sido impulsada en Ecuador por el canciller Ricardo Patiño, quien en marzo del 2014 dijo que "América del Sur es la región con mayor número de 
litigios abiertos en tribunales internacionales, por lo que se impone buscar una salida regional a esos conflictos", además recordó que en Guyana, el 26 de noviembre de 2010, Ecuador presentó la propuesta, que fue aprobada por los jefes y jefas de Estado. En el documento constan: Creación de un Centro de Arbitraje; Constitución de un Centro de Asesoría Legal para Controversias en Materia de Inversiones; y Código de Conductas para Árbitros y Mediadores de UNASUR, conjuntamente a ello indicó que por razones como los fallos contradictorios, la gran complejidad de la litigación así como los altísimos costos procesales que demandan dichas controversias, es algo no solo posible sino necesario. Por otra parte del grupo de trabajo de la instancia legal se afirma que la diferencia de este nuevo ente con los tribunales internacionales actuales como el CIADI, es que no sólo se busque un laudo, que por su esencia es inapelable, sino que "lo principal será resolver la controversia, para lo que las partes pueden solicitar que se apliquen otros mecanismos, además del arbitraje, como la conciliación, la mediación y la facilitación, que este centro sea una alternativa que empresas y Estados escojan por el principio de autonomía de voluntad de las partes, porque les da seguridad jurídica, no por obligación".

Este Centro de arbitraje Suramericano, es una cámara arbitral de carácter permanente, autónoma e independiente destinada a resolver las controversias de inversión, que vinculan a los Estados miembros entre ellos o con terceros, siempre que de común acuerdo hayan suscrito el compromiso arbitral administrado o independiente, en equidad o en derecho. Con la facultad de tramitar y conocer las controversias surgidas de contratos internacionales, donde dos o más partes se obligan hacer o no hacer algo, cuyo cumplimiento afecta a más de una economía nacional vinculada a distintos ordenamientos jurídicos vigentes de los Estados Suramericanos, terceros países y transnacionales.

Cabe destacar, que la neutralidad y la imparcialidad la garantiza el hecho de que ni los Estados miembros, ni los inversionistas tengan incidencia ni eligiendo, ni pagando los honorarios de los árbitros para evitar así "comprar la justicia", y que un asesor jurídico de una transnacional sea a su vez el tercero que tiene poder de decidir el choque de intereses que afecta a su representado.

El fín último, es crear un mecanismo alternativo de resolución de controversias que sea equitativo, oportuno, eficiente, transparente, con costos razonables y no dependientes de las partes en busca de eliminar aspectos que indican en la no imparcialidad, mediante la creación de un mecanismo regional que elimine las diferencias en materia de inversiones, permitiendo la consolidación de una Soberanía jurídica e institucional de la región, puesto que el CIADI, como se ha pretendido demostrar con el análisis del caso Exxon Mobil versus PDVSA, se caracteriza entre otros, por los siguientes aspectos o elementos: 1. Imparcialidad, que ha 
sido a veces cuestionada por que se les paga a los árbitros por las partes y se tiene sospechas que se convierten en abogados y no en árbitros imparciales. 2. Costo, que es muy elevado y quienes no tienen inmensos recursos no tiene la accesibilidad, porque es justicia privatizada y paga por las partes. Qué pasa con quienes no pueden acceder a ella?; se deberían quedar en indefensión. 3. Composición de un sistema auto referencial y hermético, en donde se determina y elige por las partes (cada uno de ellos) al árbitro, quien debe resolver su caso, porque se cree o presiente, que "el que paga", tiene el derecho de "haber comprado el servicio que se quiere" (el laudo a su favor), cuando la justicia, si bien es un servicio, no puede estar a condición de lo que aspira quien compra o paga por dicho servicio, sino de quien tiene el verdadero derecho y razón para aquello (y esté demostrado procesalmente), así "no pueda pagarlo o comprarlo". 4. Argumentos débiles de competencia, puesto que el ingreso para ser Árbitro, no es tan democrático, no solo se ingresa por méritos y capacidades, sino por relaciones. 5. sistema de indemnizaciones millonarias, que no responde a la realidad de todas las partes, sino de las élites económicas, con lo que aleja la oportunidad de acceder y de esta forma no se tutela los derechos de accesibilidad. 6. Posibilidad de pronunciamientos contradictorios, ya que por una parte se ha criticado que ciertos árbitros, en ciertos casos, han tenido determinada tendencia al resolver, y cuando, han sido seleccionados en casos similares por la parte del otro criterio divergente al anterior, han conseguido igual un criterio favorable al criterio opuesto al primer caso, lo que demuestra que a veces los Árbitros se convierten en abogados, desnaturalizando el sistema y el objetivo de la justicia; por su condición Ad hoc y no con carácter permanente.

\section{REFERENCIAS BIBLIOGRÁFICAS}

BLOCH, Roberto D. Solución de Controversias en el Mercosur. Buenos Aires: Ad Hoc, 1995.

DIENA, Julio. Derecho Internacional Público. Traducción de la 4a ed. Italiana. Barcelona: Bosch, 1948.

MORENO LOAYZA, Guadalupe. El Tribunal de Justicia del Acuerdo de Cartagena como medio jurídico de solución de controversias: estudio 4. Quito: Publicaciones del Tribunal, 1987.

SALGADO, Oswaldo. Colección Sendero Suramericano del Siglo 21: El $A B C$ del Derecho para la integración. Quito: EDISLAT, 2010. Tomo 1.

"Sarmiento Nuñez Consulting" [en línea]. 2007. [consultado 4 de febrero de 2015]. Disponible en: <http://www.snconsult.com/>.

VALENCIA RODRÍGUEZ, Luis. Principios de las Naciones Unidas. Quito: Editorial Casa de la Cultura Ecuatoriana, 1972.

VEGA, H. Integración Económica y Globalidad América Latina y el Caribe. Santiago de Chile: Ediciones Tierra Mía. 2001. 